\title{
Vulnerability of grain crops and croplands in the Midwest to climatic variability and adaptation strategies
}

\author{
J. L. Hatfield ${ }^{1}$ (D) $\cdot$ Lois Wright-Morton ${ }^{2} \cdot$ Beth Hall $^{3}$
}

Received: 4 November 2016/Accepted: 24 May 2017 /Published online: 12 June 2017

(C) The Author(s) 2017. This article is an open access publication

\begin{abstract}
Maize (Zea mays L.) and soybean (Glycine max (L.) Merr.) are the dominant grain crops across the Midwest and are grown on $75 \%$ of the arable land with small but economically important crops of wheat (Triticum aestivum L.) and oats (Avena sativa L.) but economically important crops. Historically, there have been variations in annual yields for maize and soybean related to the seasonal weather patterns. Key concerns are the impacts of future climate change on maize and soybean production and their vulnerability to future climate changes. To evaluate these, we analyzed the yield gaps as the difference between the attainable and actual yield at the county level and observed meteorological data to determine which seasonal meteorological variables were dominant in quantifying the actual/attainable yields. July maximum temperatures, August minimum temperatures, and July-August total precipitation were found to be the significant factors affecting the yield gap. These relationships were used to estimate the change in the yield gap through 2100 using both the RCP 4.5 and 8.5 climate scenarios for these variables for selected counties across the Midwest. Yield gaps increased with time for maize
\end{abstract}

Contribution from the USDA-ARS and Midwest Climate Hub.

This article is part of a Special Issue on "Vulnerability Assessment of US Agriculture and Forests developed by the USDA Climate Hubs” edited by Jerry L. Hatfield, Rachel Steele, Beatrice van Horne, and William Gould.

Electronic supplementary material The online version of this article (doi:10.1007/s10584-017-1997-x) contains supplementary material, which is available to authorized users.

J. L. Hatfield

jerry.hatfield@ars.usda.gov

Lois Wright-Morton

lwmorton@iastate.edu

Beth Hall

bethhall@illinois.edu

1 Laboratory Director and Supervisory Plant Physiologist, National Laboratory for Agriculture and the Environment, 1015 N. University Blvd., Ames, IA 50011, USA

2 Department of Rural Sociology, Iowa State University, Ames, IA 50011, USA

3 Midwest Regional Climate Center, University of Illinois, Urbana, IL 61801, USA 
across the Midwest with the largest increases in the southern portion of the Corn Belt showing a large north-south gradient in the increase of the yield gap and minimal east-west gradient. Soybean was not as sensitive as maize because the projected temperatures do not exceed optimum temperature ranges for growth and reductions in production that are more sensitive to precipitation changes during the reproductive stages. Adaptation strategies for maize and soybean will require more innovation than simple agronomic management and require the linkage between geneticists, agronomists, and agricultural meteorologists to develop innovative strategies to preserve production in the Midwest.

\section{Introduction}

Midwestern states are dominated by grain production with the area planted with maize (Zea mays L.) in 2015 of $21 \mathrm{M}$ ha, soybeans (Glycine $\max$ (L.) Merr.) with $18 \mathrm{M}$ ha, wheat (Triticum aestivum L.) at 1.8 M ha, and oats (Avena sativa L.) planted on $0.37 \mathrm{M}$ ha across the eight states. Maize and soybean occupy the vast majority of the grain crops and have a market value of $\$ 28$ billion US for maize and \$21 billion US for soybean based on 2015 commodity prices; however, wheat ( $\$ 1.8$ billion US) and oats ( $\$ 1.2$ billion US) contribute to the local economies of the Midwest and to the world economies. Productivity of these crops has increased since 1950 with the introduction of improved technologies including genetics, fertilizers, pest management, and equipment. Improved technologies have increased productivity per unit of land; however, variation in productivity remains a function of the weather during the growing season. Examination of the annual yields at the field, county, or state level for these commodities across the Midwest reveal that there is a variation among years that is expected to increase in the future under a more uncertain climate regime with more variable precipitation and extreme temperature events. In the context of vulnerability, the grain production enterprise across the Midwestern states is susceptible to the changing climate and increasing climate variability will lead to more variation in production. In this paper, we will focus on the vulnerabilities of Midwestern maize and soybean production to climate scenarios through 2100 .

Climate change impacts on plant production are viewed as positive under increasing carbon dioxide $\left(\mathrm{CO}_{2}\right)$ concentrations, negative with increasing temperatures, and variable with precipitation timing and amounts (Hatfield et al. 2011; Walthall et al. 2012). Increasing $\mathrm{CO}_{2}$ enhances production and improves water use efficiency which is important in areas with limited precipitation (Hatfield et al. 2011). Effects of increased temperatures have shown a large degree of variation with projections of reduced production by less than $5 \%$ with temperature increases of $1{ }^{\circ} \mathrm{C}$ (Hatfield et al. 2011) to over $50 \%$ in maize and soybean with $4{ }^{\circ} \mathrm{C}$ increases (Schlenker and Roberts 2009). Temperature effects on crop productivity are complex; however, one effect is consistent with increasing temperatures in that they hasten the rate of phenological development. This results in a smaller plant with reduced productivity because of the shortened growth cycle (Hatfield et al. 2011). Extreme temperature events during the pollination stage can have a large impact on productivity because of the sensitivity of the pollen to dehydration under high temperatures (Hatfield et al. 2011). Hatfield and Prueger (2015) and Hatfield (2016), using controlled environment studies with temperatures greater than or equal to $3{ }^{\circ} \mathrm{C}$ above normal temperatures, showed maize yield reductions of over $50 \%$ in grain yield along with an increased rate of phenology. Ordóñeza et al. (2015) under field conditions observed maize yield reductions from 13 to $88 \%$ due to increased temperature (over $6{ }^{\circ} \mathrm{C}$ above normal temperatures). The impact of the high temperatures occurred during the grain-filling period which was attributed to the 
impact of high temperatures on pollen survivability and high nighttime temperatures on the efficiency of the grain-filling process.

Increasing temperatures have shown a range of negative impacts on plant growth different crops. Lobell and Field (2007) found maize yields decreased $8.3 \%$ per $1{ }^{\circ} \mathrm{C}$ rise without any additional effect due to water stress which was confirmed by Mishra and Cherkauer (2010) for Midwest maize and soybean grain yields. Asseng et al. (2015) used 30 different wheat models to simulate wheat production in different world environments, and observed grain production would decrease $6 \%$ per $1{ }^{\circ} \mathrm{C}$ rise, becoming more variable in both space and time. These projections for wheat are similar to the $5.3 \%$ yield reduction per $1{ }^{\circ} \mathrm{C}$ observed in Australia by Innes et al. (2015) using a combination of experimental results coupled with simulation models. Tack et al. (2015), using historical yield trials and meteorological data for Kansas, found a combination of freezing and warming impacts were responsible for yield variations. They observed a $40 \%$ reduction in wheat yields with a $4{ }^{\circ} \mathrm{C}$ temperature increase and that newer varieties were less able to resist heat stress above $34^{\circ} \mathrm{C}$ than older varieties. There is a differential response of plants to temperature throughout the growth cycle and the results by Laza et al. (2015) for rice showed high night temperatures had no effect during the vegetative stage; however, high nighttime temperatures during the reproductive stage reduced yields because of the increased dark respiration rate and spikelet degeneration.

Temperature is only one limitation to crop productivity because drought and short-term water deficits can reduce growth and grain yield, as well. Boyer (1982) found $41 \%$ of crop losses in the USA were caused by drought, while excess water causes crop losses of $16 \%$ of the yield. Wang et al. (2016) found across Midwestern US maize yields between 1991 and 2010 were negatively correlated with drought stress in the early and middle reproductive growth stages because these phenological stages are related to grain yield. They evaluated the difference between drought stress and aeration stress and found drought stress was the dominant factor even though the Midwest is subjected to increased precipitation in the spring. In a recent review of climate adaptation strategies for European agriculture, Semenov et al. (2014) proposed that a better understanding of higher temperatures and drought stresses during the booting and flowering periods in wheat would provide guidance on how to reduce losses in grain numbers and potential grain weight. One method of avoiding drought stress would be to improve water availability through more extensive root system and changes in root architecture. Improved aeration of the root system would require improved soil structure to facilitate gas exchange between the root system and the atmosphere.

Changes in the productivity of agricultural systems are the most used indicator of climate impacts. Current literature has utilized the development and application of the yield gap concept (Licker et al. 2010; van Bussel et al. 2015). The yield gap is simply stated as the difference between the potential and actual yield. This approach allows for a quantitative assessment of the ability of the crop to achieve its potential yield, and the inability of closing the yield gap can often be ascribed to climatic stress. Egli and Hatfield (2014a, b)utilized this concept to evaluate yield gaps across the Midwest for maize and soybean. The need for increased food production to meet population demands will require a decrease in the yield gap.

The vulnerability assessment for Midwest grain crops; maize, soybean, wheat, and oats, was conducted to determine the cause of the yield gap and to extend these relationships to quantify the potential impacts on the yield gap with future climate scenarios using Iowa and Illinois as the primary states for this assessment. Reducing the vulnerability due to weather variation within the growing season will require adaptation strategies to offset the impacts of climate change across the Midwest. This paper focuses on our current understanding of the 
vulnerabilities in grain production and the potential for increased impacts on production due to climate change.

\section{Methods}

\subsection{Yield gap analysis}

County level yield data were extracted from the USDA-National Agriculture Statistics Service (NASS) for maize, soybean, wheat, and oats for all of the counties in the Midwest. Data were retrieved from 1950 through 2015 (www.nass.usda.gov) to represent the current era of agriculture with technology applications. Attainable yield was estimated using the upper quadrant analysis procedure from SAS (SAS9.3, Cary, NC) and chosen to represent the conditions in which weather was optimum during the growing season and did not present a limitation to production. The yield gap was calculated as the difference between the attainable and actual yield for each year. The ratio of actual/attainable yield was used to normalize the effects across all years. An example of the attainable, actual, and yield gap is shown in Fig. 1 for Story County, Iowa for maize.

To evaluate the effect of weather conditions during each growing season, county level meteorological data were assembled using monthly averages obtained from the Midwest Regional Climate Center (MRCC, mrcc.isws.illiois.edu) via the Applied Climate Information System (ACIS, www.rcc-acis.org) that hosts historical climate observations from federally supported sites. Regression analyses (Spearman rank method) were conducted after finding the actual/attainable yields were normally distributed on the fraction of actual/attainable yield with summer maximum temperatures, summer minimum temperatures, and monthly total precipitation for the growing season. July maximum temperatures, August minimum temperatures, and July-August total precipitation were found to be the most consistent parameters to use in further analyses. The use of the monthly averages does not account for the extremes in high-temperature events nor the contribution of isolated yet heavy rainfall events during these months.

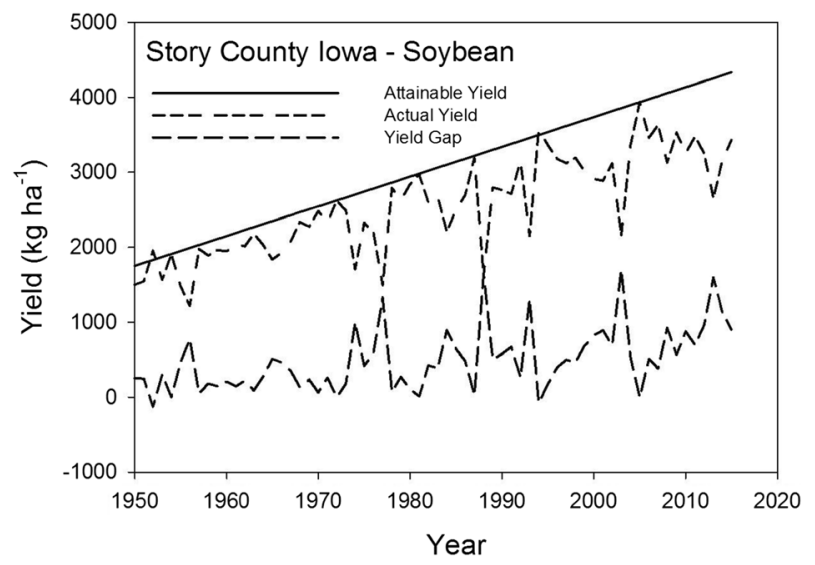

Fig. 1 Observed maize yields for Story County, Iowa for the period from 1950 through 2015 with the attainable yield line fit with the upper quadrant analysis and the yield gap calculated as attainable-actual yield. Maize yield data obtained from USDA-NASS (www.nass.usda.gov, Quickstats 2.0) 


\subsection{Climate scenarios}

To evaluate the impact of climate scenarios on the yield gap fraction, the RCP 4.5 and RCP 8.5 scenarios were used based on projections obtained from the Climate Explorer database (www. toolkit.climate.gov/climate-explorer2). The Climate Explorer database is developed from CIMP5 simulation data using an ensemble of climate models with the results statistically downscaled to represent RCP 4.5 and RCP 8.5 scenarios. Data were extracted for the projected maximum and minimum temperatures and precipitation for each month for each county to assemble a time series from 2025 through 2100. These data were used in the analysis of future climate scenarios on projected yield gaps using temperature and precipitation projections. The assembled data included the upper and lower confidence limits on these projections and were included in the analysis to provide an estimate of the variation in expected production. Projections of the July maximum temperatures for RCP 4.5 and 8.5 scenarios with the upper and lower confidence limits in northern Illinois suggest an increase from $32.5^{\circ} \mathrm{C}\left(26-38^{\circ} \mathrm{C}\right)$ in 2025 to $37.5^{\circ} \mathrm{C}\left(31-43{ }^{\circ} \mathrm{C}\right)$ in 2075 . This places the maize crop with potential exposure above $35^{\circ} \mathrm{C}$ during the pollination stage and lead to pollen death. Projections of July maximum temperature, August minimum temperatures, and JulyAugust total precipitation for a northern and southern county in Iowa and Illinois showed large differences in the expected temperature trends with less difference in precipitation across the northsouth gradient (Supplemental Figures S.1, S.2, and S.3).

\section{Results and discussion}

\subsection{Yield gap analysis}

Yield gaps expressed as actual/attainable yield ratio were used in a regression analysis for all counties in the Midwest relative to climatic variables. Actual/attainable yield has remained relatively consistent over the past 65 years with an average of $0.85(0.5-1.0)$ for both maize and soybean. There has not been a closing of the yield gap over this period, and there was no detectable trend over time in changes in the fraction of actual/attainable yield for either crop (Supplemental Figure S.4). Across the counties of the Midwest, there were differences in the patterns for the yield gaps over time indicative of the weather conditions for that location during the growing season. This provides confidence that the yield gaps can be related to weather conditions during the growing season without an interaction with technology trends.

The most consistent climate parameters, based on significance of the regression coefficients and consistency in the sign of the coefficients from the regression analysis, were July maximum temperatures, August minimum temperatures, and July-August precipitation totals. These effects were determined first by using each single variable relative the actual/attainable yield. July maximum temperatures showed a response for each state with a decrease in the yield gap with average temperatures above $30^{\circ} \mathrm{C}$ as illustrated in the results from Illinois (Fig. 2). Plants exposed to high maximum temperatures in July coincide with the pollination phase for maize which is extremely sensitive to exposure to high temperatures (Hatfield et al. 2011). Exposure to increased August minimum temperatures above $17^{\circ} \mathrm{C}$ in August also increased the yield gap (Fig. 3). Phenologically, both maize and soybean crops are in the reproductive stage with rapid grain-filling during August and higher minimum temperatures during this stage have been shown to decrease grain yield (Innes et al. 2015; Laza et al. 2015; Hatfield 2016). Soybeans produced in the Midwest are less impacted with a greater degree of flexibility in response of the grain-filling period to 


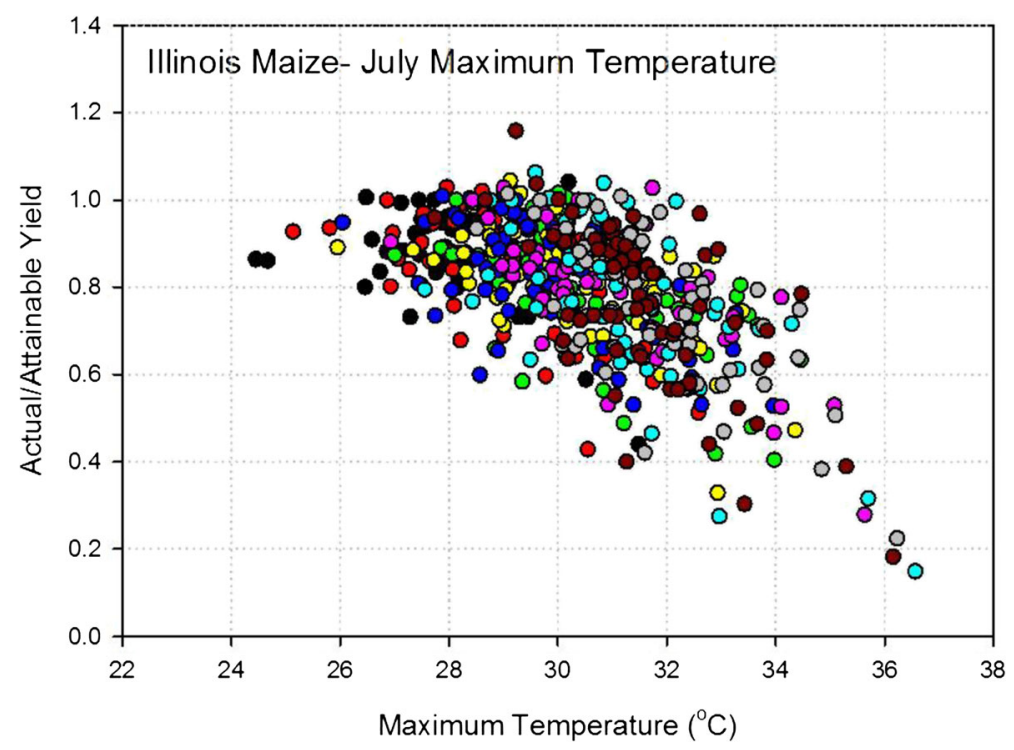

Fig. 2 Variation in the actual/attainable maize yield for all cropping districts Illinois over the period from 1950 to 2015 relative to July maximum air temperature. Maize yield data obtained from USDA-NASS (www.nass.usda. gov, Quickstats 2.0)

environmental conditions. There is a large amount of scatter (variability) in the yield gaps during periods in which temperature is not limiting, making variability attributable to limitations in available soil water during this phenological period.

If we examine the relationship with July-August precipitation, there is an effect of below normal precipitation and a minor effect of above normal precipitation (Fig. 4). July-August total precipitation below $150 \mathrm{~mm}$ showed a decrease in the maize actual/attainable yield and a similar break point for soybean production across the Midwest. Deficit soil water conditions limit the ability of the crop to maintain optimum growth during the grain-filling period. However, excess precipitation occurs more often in the Midwest and limits grain-filling, possibly due to reduction in radiation levels associated with cloudy/rainy days. This is similar the findings reported by Boyer (1982) and Mishra and Cherkauer (2010) for Midwest growing conditions.

The relationships between these variables and actual/attainable yield in soybean showed similar relationships as those for maize (not shown). July temperatures above $32{ }^{\circ} \mathrm{C}$ increased the yield gap while August minimums in excess of $20^{\circ} \mathrm{C}$ increased the yield gap. Soybean across the Midwest exhibited a decline in the actual/attainable yield as the July-August precipitation began to decrease below $200 \mathrm{~mm}$. There is a $3{ }^{\circ} \mathrm{C}$ difference between maize and soybean when August minimum temperatures began to affect grain yields and a $2{ }^{\circ} \mathrm{C}$ difference in the July maximum temperatures.

Combining these three variables into a multiple regression for the fraction of actual/attainable yield showed variation among cropping districts within each Midwestern state; however, these variables represented the best fit to the yield gap and fraction of actual/attainable yield data. As July and August temperatures increased, there was a decrease in the actual/attainable yields for all sites and increasing precipitation offsets the temperature effects; however, the magnitude of the coefficients showed that although the effect of precipitation was significant, the impact was relatively minor in maize compared to the temperature effects and showed a larger coefficient in soybean. These regression equations had significant coefficients and significant $r^{2}$ values. There 


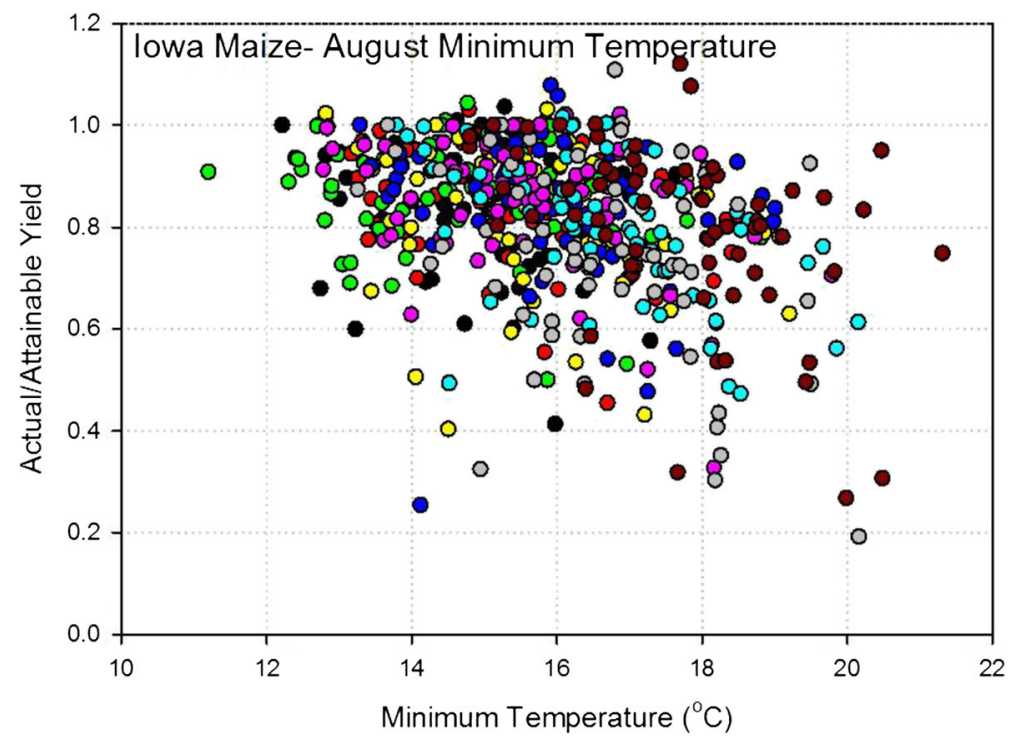

Fig. 3 Variation in the actual/attainable maize yield for all cropping districts in Iowa over the period from 1950 to 2015 relative to August minimum air temperature. Maize yield data obtained from USDA-NASS (www.nass. usda.gov, Quickstats 2.0)

were differences among the coefficients for the regression equations especially at the cropping district level with very similar coefficients for counties within a cropping district. To validate the approach, a regression equation within the same cropping district was used to estimate the actual/ attainable yield for an adjacent county to compare actual vs predicted results using the observed monthly values for the variables. The results showed that we could estimate the period from 1950

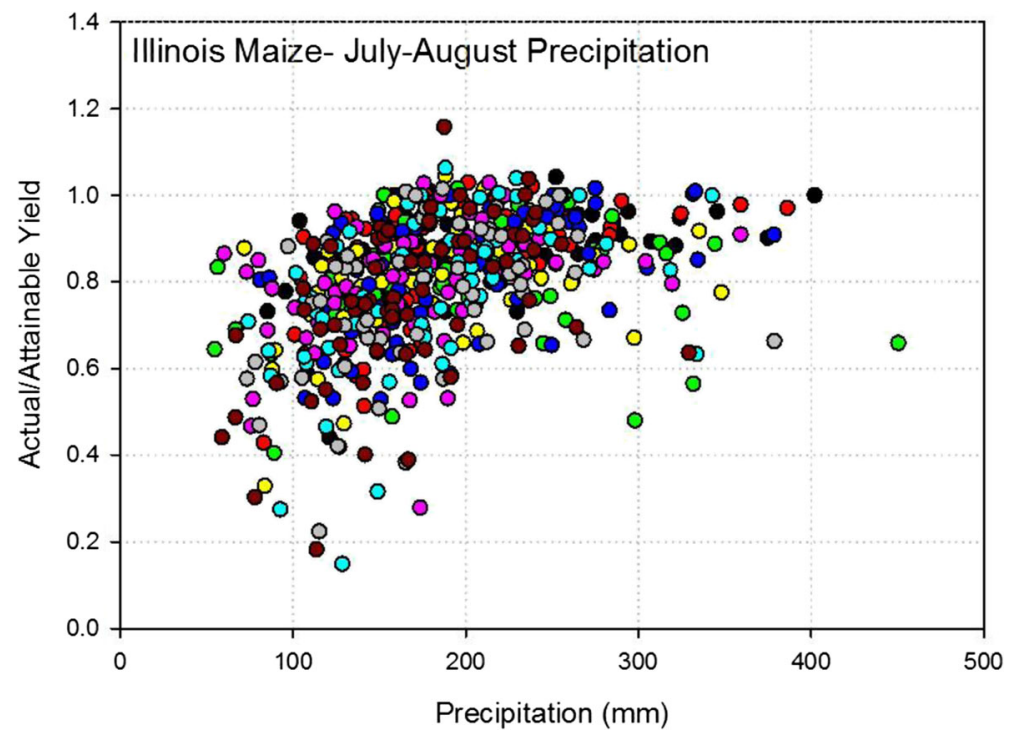

Fig. 4 Variation in the actual/attainable maize yield for all cropping districts in Illinois over the period from 1950 to 2015 relative to July-August total precipitation. Maize yield data obtained from USDA-NASS (www.nass. usda.gov, Quickstats 2.0) 
through 2015 with a correlation of 0.95 and, using a $t$ test, there were no differences between the estimated and predicted values. This provided confidence that this approach was robust in terms of estimating the future impacts with these variables.

\subsection{Projected yields for maize and soybean}

To project the yields through the remainder of this century, monthly values for temperature and precipitation in July and August were used in regression equation specific to each county. We aggregated individual counties into cropping districts for Iowa and Illinois because these two states are dominant in maize and soybean production and supplemented with individual counties across the Midwest to evaluate the extent of the change in the yield gap. Cropping districts were selected for aggregation because these represent similar production areas and a greater confidence in the stability of the climate projections. Projected actual/attainable maize yields demonstrated a significant decrease through the remainder of the century with the magnitude of the decrease dependent upon the location across the Midwest. Increasing July maximum and August minimum temperatures continued to place a stress on the crop during the grain-filling stage and reduced yields. If we assume that maize yields would continue to increase similar to the trend shown in Fig. 1, then the actual yield will decrease and widen the yield gap through 2100. The estimated attainable maize yields are not unreasonable because of the expected continued improvement in genetics and technology that facilitate increased yields and would represent the upper boundary of the achievable production across the Midwest. Southern areas Iowa and Illinois showed a larger decline in actual/attainable yield fraction (i.e., an increase in the yield gap) because of the greater temperature increase in the July-August period while northern areas showed a smaller decrease in actual/ attainable yield fraction (Fig. 5). The uncertainty about the expected temperature values over the remainder of the century leads to large variation in the expected yields; however, the trends remain consistent for both the RCP 4.5 and 8.5 scenarios. These are average monthly values for temperature and precipitation; however, the uncertainty ranges should encompass the expected range of variation potentially encountered by the maize crop at a specific location and these results indicate a decrease in the actual/attainable yields for maize. Exposure of the maize crop to temperatures in excess of the upper physiological threshold will create increased vulnerability of the maize crop to climate change. There have been several attempts to use crop models to simulate the effects of drought and temperature stress on maize production in the Midwest (Jin et al. 2016). They concluded that to estimate the impacts of future climate assessments, crop models would have to incorporate the effects of minimum temperatures and interactions among stresses which we found to be the case in the analysis of the yield gaps for the Midwest.

The trends in the northern portion of the Corn Belt show less impact of climate change on maize yields than the southern counties (Fig. 5). There is a distinct gradient from north to south but less of a gradient from east to west because the changes in temperature along a latitudinal gradient are expected to remain consistent. The Corn Belt will move northward with the increasing temperatures, and yield decreases in the southern Corn Belt creating a situation in which the economic return on maize will be insufficient and shifts in planted area to maize will be reduced. The projected monthly precipitation amounts through 2050 decrease significantly (Supplemental Figure S.3), as shown in the differences between southern and northern counties in Iowa and Illinois, below the threshold where soil water availability impacts yield and could therefore lead to a greater reduction on corn and soybean production.

Projected actual/attainable yields for soybean across Iowa and Illinois show a different pattern than maize (Fig. 6). There is still a decrease in yield over the remainder of the century; however, 


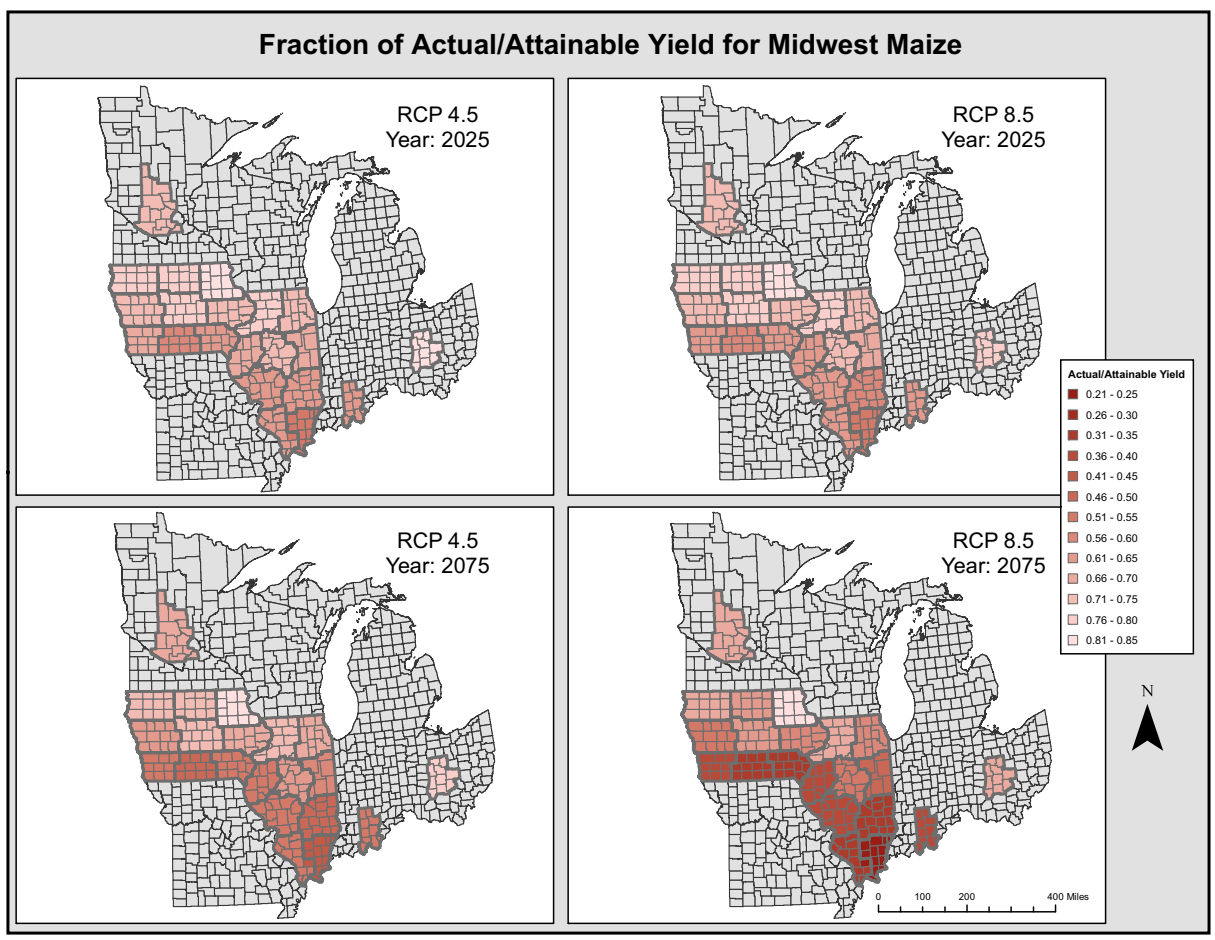

Fig. 5 Projected yield gaps (actual/attainable yield) for maize across Iowa and Illinois cropping districts and selected Midwestern counties following RCP 4.5 and 8.5 projections for temperature and precipitation for 2025 and 2075

the magnitude of the change is much smaller. Increases in temperature place a stress on the crop but do not exceed the upper temperature threshold by similar amounts as found for maize. These results are consistent with the observations by Hatfield et al. (2011) where soybean in the southern USA could be expected to demonstrate a reduced yield because of the higher temperatures while soybean in the Midwest would benefit and actually increase yield because the temperature increase would still be within the optimum temperature range. Siebers et al. (2015) found heat waves with increases of $6{ }^{\circ} \mathrm{C}$ above normal in the early and late reproductive stages (i.e., July and August) reduced soybean yield even though the remainder of the season was near normal. The projected actual/attainable yield for the northern areas of the Midwest show an average fraction of 0.8 to 0.85 which is similar to the observed fraction for the past 65 years. This demonstrates that the projected changes in temperature will have minor impact on production and water availability will be the dominant factor affecting production. There is a decline in actual/attainable yields in the southern counties of the Midwest that are below the averages yields observed in the period from 1950 to 2015; however, these decreases are not of the magnitude to reduce the economic viability of this crop.

\subsection{Vulnerability of grain production in the Midwest}

It is commonly assumed that water limitations are the primary factor affecting maize and soybean production in the Midwest; however, increases in temperature will have a greater impact on maize production with precipitation availability the primary factor in soybean production. There 
are physiological responses to the increases in the July maximum and August minimum temperatures. These outweigh the effect of early season increases in air temperature which are expected to change as well. For maize and soybean, the grain-filling period is the most sensitive to temperatures outside of the optimum temperature range. Increases in late summer temperature coinciding with grain-filling increase the vulnerability of these crops to climate change. Precipitation patterns are expected to continue to change throughout the remainder of the century with more spring and reduced summer precipitation associated with increased variability. Increased precipitation in the spring has a greater impact on maintaining planted area until harvest because years with excessive precipitation in the spring are the production years with the largest difference between planted and harvested area for both crops. All of these factors will contribute to the reductions in grain yield for maize and soybean. Vulnerabilities will also increase because of the increased likelihood of more extreme events.

Analysis of the yield gaps for wheat in the Midwest revealed that increases in temperature through 2100 would have a minor impact on the yield gap. Change in the climate that will impact both oats and wheat in the Midwest is the expected increase in spring precipitation that could interfere with planting (oats) and harvest (oats and wheat) and potentially lead to decreased grain quality. In the years where spring precipitation has been above normal, grain yields have exhibited the largest yield gaps.

Water management in the Midwest has been commonly expected to be the key to preserving maize and soybean yields; however, these results indicate that the changing temperature will be a more dominant factor affecting grain yields as it has both direct (phenology, photosynthesis,

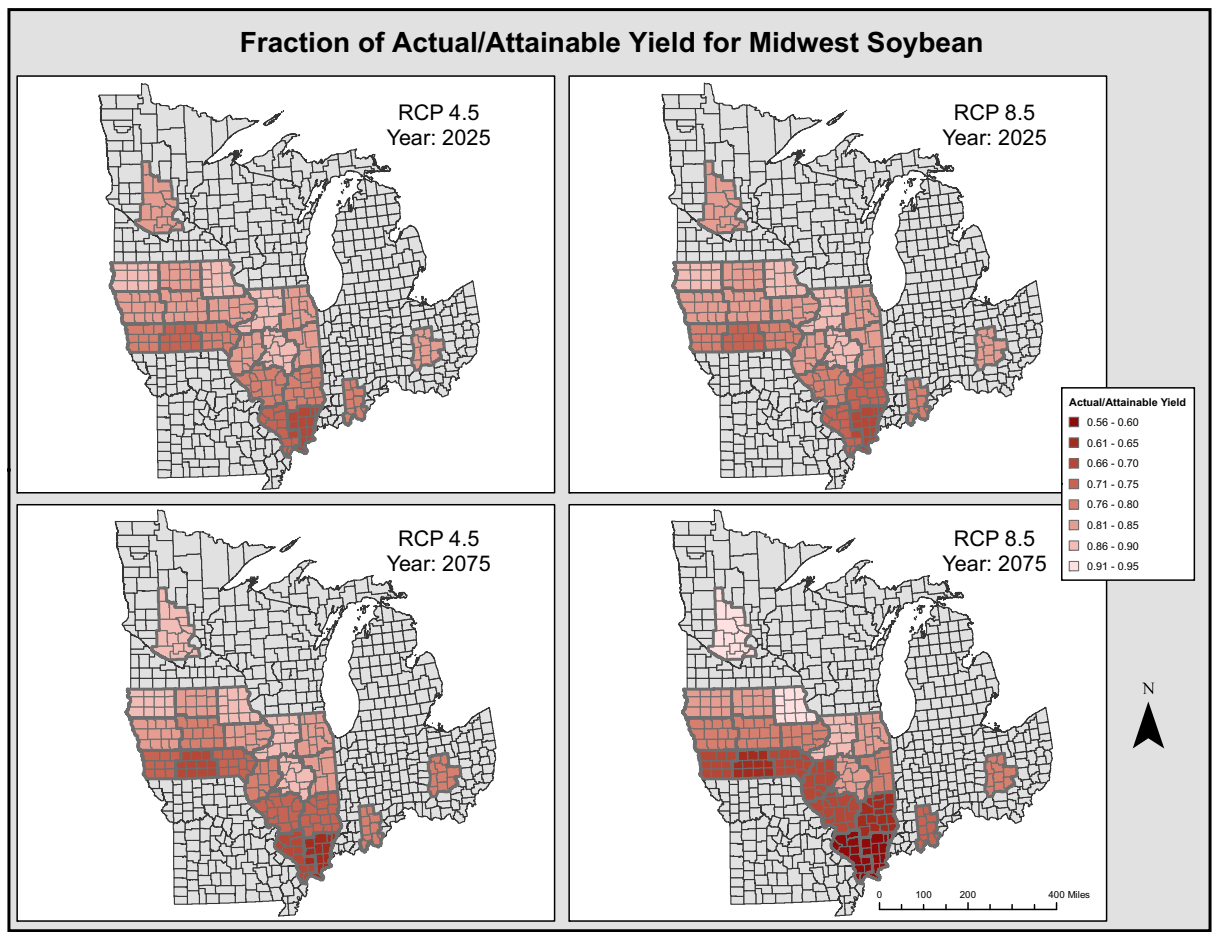

Fig. 6 Projected yield gaps (actual/attainable yield) for soybean across Iowa and Illinois cropping districts and selected Midwestern counties following RCP 4.5 and 8.5 projections for temperature and precipitation for 2025 and 2075 
respiration, leaf senescence) and indirect effects on crop production (higher ET thus water stress, and higher grain $\mathrm{N}$ concentration thus more need for $\mathrm{N}$ supply and likely nitrogen stress). Exposure to high temperatures for maize and soybean limit productivity because of the disruption of the efficiency of the pollination process (July maximum temperatures) and efficiency of the grainfilling process (August minimum temperatures). Temperature ranges for both maize and soybean are consistent across genetic material and increasing temperatures will have large impacts on productivity because of these set temperature ranges. The large impacts on production predicted by Schlenker and Roberts (2009) and Hatfield (2016) need to be considered carefully when evaluating the climate impacts on crop production due to climate change.

\section{Adaptation strategies}

A key message of the Third US National Climate Assessment and underlying technical reports is that crop production will be able to adapt to the changing climate until mid-century when major disruptions in production are expected to occur (Walthall et al. 2012; Hatfield et al. 2014; Melillo et al. 2014). The results of this study are further evidence of this conclusion as projected temperature increases overwhelm the ability of adaptation strategies to offset direct climate impacts. Corn Belt farmers are currently adapting to changes in their local climate by investing in precision agriculture, artificially draining their lands, using no-tillage, increasing their use of cover crops, utilizing weather technologies to make management decisions, and implementing other strategies to maintain yields (Morton et al. 2015; Church et al. 2015). More than $86 \%$ of upper Midwest farmers use short-term weather information to make planting, fertilization, harvest decisions, and other farm decisions (Church et al. 2015). These adaptations are changes at the margin and have some benefits under moderate climate change for some cropping systems; however, there are limits to their effectiveness under more extreme conditions (Howden et al. 2007).

Current policies and practices which target farm-level adaptive management decisions may not be able to fully cope with increasing variability in climate and extreme temperature and precipitation events (Howden et al. 2007). Sixty-five percent of Corn Belt farmers make their seed variety selection and purchases in November-December prior to spring planting. They report longer term seasonal and annual weather information has no or low influence on their decisions (Church et al. 2015). These low levels of confidence in the accuracy of longer term predictions that could be used to make seed selections in anticipation of drought or excess rain reflect both perceptions and current limitations of downscaled climate science relevant to localized decisions. Planting dates may be determined by the workable conditions in the spring, and the increases in spring precipitation have reduced the number of workable field days (Walthall et al. 2012). In many areas, intraseasonal variability makes planning for spring field conditions, mid-season fertilizer, and herbicide management, and preventing late season heat stress complicated. Changing planting dates to avoid late season heat stress or using earlier maturing genetic material to avoid the late season temperature increases may not be sufficient to reduce the yield gap in the southern portions of the Corn Belt. Currently, farm-level risk management strategies in the region range from $58 \%$ of farmers purchasing additional crop insurance; $42 \%$ adding in new technologies, $63 \%$ implementing infield conservation practices, and 34\% putting in place edge of field conservation practices (Church et al. 2015). While these adaptations are important to reduce soil loss, improve soil structure and water holding capacity, and protect some farm income, they are likely insufficient to address the increased rate of phenology that affects grain yields in locations where heat temperatures exceed thresholds for pollen survivability and the grain fill processes. 
Larger scale, more transformative technologies, policies, and incentives are needed that target landscape level adaptations. Regionally, one adaptation strategy that has already begun is to shift the Corn Belt to more northern latitudes where temperatures are not projected to be above the upper threshold for growth; and where precipitation is increasing based on USDANASS county level planted area to maize. Another adaptation strategy would be to shift to a different mixture of crops rather than maize and soybean which currently occupy $75 \%$ of the arable land area in the Midwestern states. Major changes in cropping systems and land use will need incentives and resource support to develop new infrastructure and to re-locate labor and industries to be closer to production.

Adaptation strategies at all scales will need to go beyond genetics and agronomic management. In this analysis, there is not a consideration of the indirect impacts on production due to the potential increases in pest populations and stresses on crop production. Further, this analysis does not account for the human-social institution aspects that are critical to responding to climate changes. While biophysical sciences can evaluate the impacts of adaptive management and project future trajectories, climate change is really a social problem (Grundmann 2016). Its impacts affect and are influenced by people. The problem of a growing population and an increased projected per capita food demand will require society to make climate change a priority. Society needs to invest in expanding potential attainable crop yields and find new and different ways of reducing the gap between actual and attainable yields. This is not a climate change problem but one of social perspectives, cultural values, and public discourse (Grundmann 2016) which must aggressively be linked to the sciences of genetics, agronomy, engineering, meteorology, economics, and sociology. Only then can the efforts of scientists, politicians, community and national leaders, and ordinary citizens find practical and innovative solutions (Wilke and Morton 2015).

Acknowledgements We appreciate the support of the Midwest Regional Climate Center for providing the historical climate data for the Midwest and NOAA through their Climate Explorer portal for the future climate scenarios. We are indebted to Michelle Cryder for her diligent efforts to assemble, analyze, and prepare these data analyses. Opinions expressed are those of the authors and not necessarily those of the Illinois State Water Survey, the Prairie Research Institute, or the University of Illinois.

Open Access This article is distributed under the terms of the Creative Commons Attribution 4.0 International License (http://creativecommons.org/licenses/by/4.0/), which permits unrestricted use, distribution, and reproduction in any medium, provided you give appropriate credit to the original author(s) and the source, provide a link to the Creative Commons license, and indicate if changes were made.

\section{References}

Asseng S, Ewert F, Martre P, Rötter RP, Lobell DB, Cammarao D, Kimball BA, Ottman MJ, Wall GW, White JW, Reynolds MP, Alderman PD, Prasad PVV, Aggarwal PK, Anothai J, Basso B, Biernath C, Challinor AJ, De Sanctis G, Doltra J, Fereres E, Garcia-Vila M, Gayler S, Hoggenboom G, Hunt LA, Izaurralde RC, Jabloun M, Jones CD, Kersebaum KC, Koehler A-K, Müller C, Kumar SN, Nedel C, O’Leary G, Olesen JE, Palosuo T, Priesack E, Rezaei EE, Ruane AC, Semenov MA, Shcherbak I, Stöckle C, Stratonovitch P, Streck T, Supit I, Tao F, Thorburn PJ, Waha K, Wang E, Wallach D, Wolf J, Zhao Z, Zhu Y (2015) Rising temperatures reduce global wheat production. Nat Clim Chang 5:143-147

Boyer JS (1982) Plant productivity and environment. Science 218:443-448

van Bussel LGJ, Grassini P, Van Wart J, Wolf J, Claessens L, Yang H, Boogaard H, de Groot H, Saito K, Cassman KG, van Ittersum MK (2015) From field to atlas: upscaling of location-specific yield gap estimates. Field Crop Res 177:98-108

Church, S. P., T. Haigh, M. Widhalm, L.S. Prokopy, J. G. Arbuckle Jr., J. Hobbs, T. Knoot, C. Knutson, A. Loy, A. S. Mase, J. McGuire, L. W Morton, J. Tyndall 2015 Farmer perspectives on agricultural practices, information, and weather variability in the corn belt: a Statistical Atlas, Volume 2. CSCAP-0184-2015. West Lafayette. IN 
Egli DB, Hatfield JL (2014a) Yield gaps and yield relationships in central U.S. soybean production systems. Agron J 106:560-566

Egli DB, Hatfield JL (2014b) Yield gaps and yield relationships in central U.S. maize production systems. Agron J 106:2248-2256

Grundmann R (2016) Climate change as a wicked social problem. Nat Geosci 9:562-563

Hatfield JL (2016) Increased temperatures have dramatic effects on growth and grain yield of three maize hybrids. Agric Environ Lett 1:150006. doi:10.2134/ael2015.10.0006

Hatfield JL, Prueger JH (2015) Temperature extremes: effects on plant growth and development. Weather and Climate Extremes 10:4-10

Hatfield JL, Boote KJ, Kimball BA, Ziska LH, Izaurralde RC, Ort D, Thomson AM, Wolfe DW (2011) Climate impacts on agriculture: implications for crop production. Agron J 103:351-370

Hatfield, J., G. Takle, R. Grotjahn, P. Holden, R. C. Izaurralde, T. Mader, E. Marshall, and D. Liverman. 2014. Ch. 6: Agriculture. In Melillo, J. M., T. C. Richmond, and G. W. Yohe (eds.), Climate change impacts in the United States: the third national climate assessment, U.S. Global Change Research Program, pp. 150-174. doi:10.7930/J02Z13FR. http://nca2014.globalchange.gov/report/sectors/agriculture

Howden SM, Soussana JF, Tubiello FN, Chhetri N, Dunlop M, Meinke H (2007) Adapting agriculture to climate change. PNAS 104(50):19691-19696

Innes PJ, Tan DKY, Van Ogtrop F, Amthor JS (2015) Effects of high-temperature episodes on wheat yields in New South Wales, Australia. Agric. Forest Meteorol. 208:95-107

Jin Z, Zhuang Q, Tan Z, Dukes JS, Zheng B, Melilllo JM (2016) Do maize models capture the impacts of heat and drought stresses on yield? Using algorithm ensembles to identify successful approaches. Glob Chang Biol 22:3112-3126. doi:10.1111/gcb.13376.HENONG JIN

Laza MRC, Sakai H, Cheng W, Tokida T, Peng S, Hasegawa T (2015) Differential response of rice plants to high night temperatures imposed at varying developmental phases. Agric Forest Meteorol 209210:69-77

Licker R, Johnston M, Foley JA, Barford C, Kucharik CJ, Monfreda C, Ramankutty N (2010) Mind the gap: how do climate and agricultural management explain the 'yield gap' of croplands around the world? Glob Ecol Biogeogr 19:769-782

Lobell DB, Field CB (2007) Global scale climate-crop yield relationships and the impacts of recent warming. Environ res Letters 2:1-7

Melillo JM, Richmond TC, Yohe GW (eds) (2014) Climate change impacts in the United States. The third national climate assessment. US Global Change Research Program, Washington DC, p 841

Mishra V, Cherkauer KA (2010) Retrospective droughts in the crop growing season: implications to corn and soybean yield in the Midwestern United States. Agric for Meteorol 150:1030-1045

Morton LW, Hobbs J, Arbuckle J, Loy A (2015) Upper Midwest climate variations: farmer responses to excess water risks. Journal Environmental Quality 44:810-822. doi:10.2134/jeq2014.08.0352

Ordóñeza RA, Savina R, Cossania CM, Slafera GA (2015) Yield response to heat stress as affected by nitrogen availability in maize. Field Crop res 183:184-203

Schlenker W, Roberts MJ (2009) Nonlinear temperature effects indicate severe damages to U.S. crop yields under climate change. Proc Natl Acad Sci U S a 106:15594-15598

Semenov MA, Stratonovitch P, Alghabari F, Gooding MJ (2014) Adapting wheat in Europe for climate change. J Cereal Sci 59:245-256

Siebers MH, Yendrek CR, Drag D, Locke AM, Acosta LR, Leakey ADB, Ainsworth EA, Bernacchi CJ, Ort DR (2015) Heat waves imposed during early pod development in soybean (Glycine max) cause significant yield loss despite a rapid recovery from oxidative stress. Glob Chang Biol 21:3114-3125. doi:10.1111/gcb.12935

Tack J, Barkley A, Nalley LL (2015) Effect of warming temperatures on US wheat yields. Proc Natl Acad Sci U $\mathrm{S}$ a $112: 6931-6936$

Walthall, C. L., J. Hatfield, P. Backlund, L. Lengnick, E. Marshall, M. Walsh, S. Adkins, M. Aillery, E. A. Ainsworth, C. Ammann, C. J. Anderson, I. Bartomeus, L. H. Baumgard, F. Booker, B. Bradley, D. M. Blumenthal, J. Bunce, K. Burkey, S. M. Dabney, J. A. Delgado, J. Dukes, A. Funk, K. Garrett, M. Glenn, D. A. Grantz, D. Goodrich, S. Hu, R. C. Izaurralde, R. A. C. Jones, S-H. Kim, A. D. B. Leaky, K. Lewers, T.L. Mader, A. McClung, J. Morgan, D. J. Muth, M. Nearing, D. M. Oosterhuis, D. Ort, C. Parmesan, W. T. Pettigrew, W. Polley, R. Rader, C. Rice, M. Rivington, E. Rosskopf, W. A. Salas, L. E. Sollenberger, R. Srygley, C. Stöckle, E. S. Takle, D. Timlin, J. W. White, R. Winfree, L. Wright-Morton, L. H. Ziska 2012. Climate Change and Agriculture in the United States: Effects and Adaptation. USDA Technical Bulletin 1935. Washington, DC. 186 pages

Wang R, Bowling LC, Cherkauer KA (2016) Estimation of the effects of climate variability on crop yield in the Midwest USA. Agric For Meteorol 216(141):156

Wilke AK, Morton LW (2015) Climatologists' communication of climate science to the agricultural sector. Sci Commun 38:495-522. doi:10.1177/1075547015581927 